\title{
Fibroblast Growth Factor (FGF) 23 Regulates the Plasma Levels of Parathyroid Hormone In Vivo Through the FGF Receptor in Normocalcemia, But Not in Hypocalcemia
}

\author{
Maria L. Mace Mva Gravesen $^{2}$ - Anders Nordholm ${ }^{1,2} \cdot$ Klaus Olgaard $^{2}$ • \\ Ewa Lewin ${ }^{1,2}$ (D)
}

Received: 29 June 2017/ Accepted: 22 September 2017/Published online: 23 October 2017

(c) The Author(s) 2017. This article is an open access publication

\begin{abstract}
The calcium and phosphate homeostasis is regulated by a complex interplay between parathyroid hormone (PTH), fibroblast growth factor 23 (FGF23), and calcitriol. Experimental studies have demonstrated an inhibitory effect of FG23 on PTH production and secretion; the physiological role of this regulation is however not well understood. Surprisingly, in uremia, concomitantly elevated FGF23 and PTH levels are observed. The parathyroid gland rapidly loses its responsiveness to extracellular calcium in vitro and a functional parathyroid cell line has currently not been established. Therefore, the aim of the present investigation was to study the impact of FGF23 on the $\mathrm{Ca}^{2+} / \mathrm{PTH}$ relationship in vivo under conditions of normocalcemia and hypocalcemia. Wistar rats were allocated to treatment with intravenous recombinant FGF23 and inhibition of the FGF receptor in the setting of normocalcemia and acute hypocalcemia. We demonstrated that FGF23 rapidly inhibited PTH secretion and that this effect was completely blocked by inhibition of the FGF receptor. Furthermore, inhibition of the FGF receptor by itself significantly increased PTH levels, indicating that FGF23 has a suppressive tonus on the parathyroid gland's PTH secretion. In acute hypocalcemia, there was no effect of either recombinant FGF23 or FGF receptor inhibition on the physiological response to the low ionized calcium levels. In conclusion, FGF23 has an inhibitory tonus on PTH secretion in normocalcemia and signals through the
\end{abstract}

Ewa Lewin

ewa.lewin@regionh.dk; lewin@dadlnet.dk

1 Department of Nephrology, Herlev Hospital, University of Copenhagen, 2730 Copenhagen, Denmark

2 Department of Nephrology, Rigshospitalet Copenhagen, University of Copenhagen, Copenhagen, Denmark
FGF receptor. In acute hypocalcemia, when increased PTH secretion is needed to restore the calcium homeostasis, this inhibitory effect of FGF23 is abolished.

Keywords PTH · FGF23 · FGFR · PD173074 ·

Hypocalcemia

\section{Introduction}

The primary role of parathyroid hormone (PTH) is to prevent and reverse acute hypocalcemia by mobilizing calcium from bone, stimulating renal $\mathrm{Ca}^{2+}$ reabsorption, and by promoting the production of the active vitamin $\mathrm{D}$ metabolite calcitriol [1]. Extracellular $\mathrm{Ca}^{2+}$ is the main determinant of the secretion of PTH from the parathyroid glands. The parathyroid glands express abundant calciumsensing receptor (CaSR) mRNA and protein [2]. Small changes in extracellular $\mathrm{Ca}^{2+}$ trigger CaSR-mediated intracellular $\mathrm{Ca}^{2+}$ signaling and PTH secretion [3].

The $\mathrm{Ca}^{2+} / \mathrm{PTH}$ relationship is described by a steep sigmoidal curve. A small decline in $\mathrm{Ca}^{2+}$ below normal will result in a dramatic increase in the $\mathrm{PTH}$ secretion. The maximal secretory rate, the upper part of the curve, is achieved after just a slight degree of hypocalcemia. Induction of even mild hypercalcemia will, in contrast, result in a modest decline of PTH secretion to its minimal level [1].

Several factors are involved in the complexity of the $\mathrm{Ca}^{2+} / \mathrm{PTH}$ relationship such as intraglandular degradation of PTH, recruitment of parathyroid cells in an active state, autocrine/paracrine factors, hysteresis, rate-dependent control of the PTH response to reduction of $\mathrm{Ca}^{2+}$, and several intraglandular factors. The detailed mechanism behind the complexity of the $\mathrm{Ca}^{2+}$ regulated PTH secretion is still not well understood $[4,5]$. The newly described crystal structure 
of CaSR extracellular domain brought important and fascinating new information on the mechanisms by which $\mathrm{Ca}^{2+}$ and other ions control the parathyroid function [6, 7]. Crystal structures of the resting and active conformation reveal multiple binding sites for $\mathrm{Ca}^{2+}$ and $\mathrm{PO}_{4}{ }^{3-}$ ions. While $\mathrm{Ca}^{2+}$ stabilizes the active state, $\mathrm{PO}_{4}{ }^{3-}$ ions reinforce the inactive conformation of CaSR [7]. This finding further emphasizes that calcium and phosphate homeostases are interrelated at the level of parathyroids as previously indicated by our group and others showing direct regulatory effect of phosphate on PTH secretion [8-10].

Fibroblast growth factor 23 (FGF23) activates the FGF receptor (FGFR) in the presence of the obligate co-receptor $\alpha$ Klotho and the parathyroid gland expresses both FGFRs and aKlotho [11-13]. FGF23 has been proposed to have several effects on the parathyroid glands such as decreasing PTH gene expression and secretion, increasing the parathyroid glands expressions of CaSR, vitamin D receptor (VDR), and $\alpha$ Klotho, altogether contributing to the suppression of PTH [12, 14]. Recently, it was shown that FGF23 via activation of the $\alpha$ Klotho/FGF receptor signaling is positively associated with parathyroid cell proliferation [15].

Clinical observations of either high or low FGF23 levels have shown very varied plasma PTH levels [16]. As alteration in FGF23 levels also induces changes in the levels of calcitriol, $\mathrm{Ca}^{2+}$, and phosphate, it can be difficult to unravel the direct effect of FGF23 on PTH levels. Experimental studies on the direct effect of FGF23 on the parathyroid gland have shown an inhibitory effect on PTH mRNA and hormone secretion [12, 14]. However, the physiological function of the inhibitory effect of FGF23 on the parathyroid gland's PTH gene expression and PTH secretion is not well understood. The parathyroid gland loses rapidly its responsiveness to extracellular calcium ex vivo and there has currently not been established a functional parathyroid cell line [17, 18]. Therefore, the aim of the present investigation was to study the impact of FGF23 on the $\mathrm{Ca}^{2+} / \mathrm{PTH}$ relationship in vivo under conditions of normocalcemia and hypocalcemia. The present study demonstrates for the first time that FGF23 has an inhibitory tonus on PTH secretion when plasma $\mathrm{Ca}^{2+}$ is within normal range. At low plasma $\mathrm{Ca}^{2+}$, when increased PTH secretion is needed to restore $\mathrm{Ca}^{2+}$ levels, this inhibitory effect of FGF23 on PTH secretion is abolished.

\section{Materials and Methods}

\section{Animals}

Adult male Wistar rats (200 g) were used for the study (Charles Rivers Laboratories, GmbH, Germany). They were housed in an accredited facility with a 12-h light/dark circle. The rats had free access to water and standard diet containing $0.7 \%$ calcium, $0.5 \%$ phosphorus, and $600 \mathrm{IU}$ vitamin D per kg (Altromin, Lage, Germany).

\section{Study Approval}

The experiments were conducted in accordance to the national guidelines for care and use of laboratory animals. The experimental protocols were approved by the Danish Animal Experiments Inspectorate (license 2012-DY-293400023).

\section{Experimental Protocols}

The rats were allocated to one of the following models:

(1) Treatment with recombinant FGF23 (rFGF23) in normocalcemic condition $(n=4)$.

(2) Treatment with FGF Receptor inhibitor (FGFRi) and rFGF23 in normocalcemic condition $(n=9)$.

(3) Treatment with a combination of rFGF23 or vehicle and induction of acute hypocalcemia $(n=12)$.

(4) Treatment with a combination of FGFRi or vehicle and induction of acute hypocalcemia $(n=12)$.

The rats were anesthetized with pentobarbital $(50 \mu \mathrm{g} /$ $\mathrm{kg}$ ) intraperitoneally. A catheter was placed in the femoral vein for intravenous infusion and a catheter was placed in the femoral artery for blood sampling. Blood was drawn at baseline and at times $0,5,10 \mathrm{~min}$, and subsequently every $10 \mathrm{~min}$. Same volume of isotonic saline was administered after blood sampling to restore blood volume.

We used full-length human rFGF23 (R\&D Systems, Minneapolis, MN) dissolved in sterile phosphate-buffered saline according to manufacturer's recommendation and diluted in isotonic saline to a volume of $100 \mu \mathrm{l}$. The rFGF23 was given as an intravenous bolus injection. Vehicle consisted of $100 \mu \mathrm{l}$ isotonic saline. The FGF receptor inhibitor PD173074 (L\&C Laboratory, Woburn, MA) $40 \mathrm{mg}$ was dissolved in $200 \mu \mathrm{l} 96 \%$ ethanol and administered by oral gavage. Vehicle consisted of $200 \mu \mathrm{l}$ $96 \%$ ethanol. In model 2 , increasing doses of rFGF23 were administered to groups of rats, $0.1 \mu \mathrm{g} \operatorname{rFGF} 23(n=5)$, $1 \mu \mathrm{g} \operatorname{rFGF} 23(n=2)$, and $10 \mu \mathrm{g} \operatorname{rFGF} 23(n=2)$. Acute hypocalcemia was induced by a continuous intravenous infusion of $40 \mathrm{mM}$ EGTA (ethylene-bis(oxyethylenenitrilo)tetraacetic acid; Sigma, USA) at a rate of $3.0 \mathrm{ml} / \mathrm{h}$ [19].

\section{Biochemistry}

Plasma $\mathrm{Ca}^{2+}$ was measured by a calcium selective electrode (ABL505, Radiometer, Copenhagen, Denmark). Plasma FGF23 was measured using the intact FGF23 
enzyme-linked immunosorbent assay (Kainos Laboratory, Tokyo, Japan) measuring both rat and human FGF23. The intra- and inter-assay coefficients of variation in our laboratory were 2.5 and $5 \%$, respectively [13]. PTH was measured by an ELISA method (Immutopics, San Clemente, CA). The inter-assay and intra-assay coefficients of variation of this PTH ELISA were, respectively, 9 and $4 \%$ in our laboratory [5].

\section{Statistical Analyses}

Normal distribution of data was assessed in GraphPad Prism 7. Data are expressed as mean \pm SEM. Statistical significance was tested using paired or unpaired two-sided $t$ test calculated in Excel and GraphPad Prism 7. Significance level was set at $p \leq 0.05$.

\section{Results}

\section{Effect of FGF23 and FGF Receptor Inhibition on the Plasma Levels of PTH in Normocalcemia}

To study the effect of FGF23 on PTH levels in plasma, we administered rFGF23 by an intravenous bolus injection in normal rats. The rats were given $0.1 \mu \mathrm{g}$ rFGF23 resulting in a significant increase in plasma levels of intact FGF23 from $83 \pm 21$ to $907 \pm 101 \mathrm{pg} / \mathrm{ml} \quad(p<0.01)$. The rFGF23 was rapidly cleared from the circulation and FGF23 levels became close to baseline levels after 20-30 min (Fig. 1a). This is in accordance with our previous finding of a short half-life of FGF23 [20]. The rFGF23 caused a significant decrease in the plasma levels of PTH already at $10 \mathrm{~min}(p<0.01)$ and subsequent lower levels of PTH (Fig. 1b).

In order to examine whether FGF23 was signaling through the FGF receptor, we combined administration of FGFRi PD173074 and rFGF23. FGFRi resulted in a significant decrease in plasma iFGF23 levels from $116 \pm 37$ to $21 \pm 11 \mathrm{pg} / \mathrm{ml} \quad(p<0.05)$ and in a simultaneous increase in plasma levels of PTH from $38 \pm 10$ to $270 \pm 50 \mathrm{pg} / \mathrm{ml}$ after $4 \mathrm{~h}(p<0.05$, Fig. $1 \mathrm{c})$, indicating that FGF23 signaling via the FGFR has an inhibitory tonus on PTH secretion. When $0.1 \mu \mathrm{g}$ of $\mathrm{rFGF} 23$ was given after prior FGFRi, it had no suppressive effect on the plasma levels of PTH (Fig. 1c). Increasing doses, 1 and $10 \mu \mathrm{g}$, of rFGF23 resulted in very high plasma levels of FGF23 around 12,000 and $120,000 \mathrm{pg} / \mathrm{ml}$, respectively. However, these high FGF23 levels did not suppress PTH levels when the FGFR was inhibited (data not shown).

\section{Effect of FGF23 on the Plasma Levels of PTH in During Hypocalcemia}

To study the effect of FGF23 on PTH secretion in the setting of hypocalcemia, the parathyroid glands' PTH secretion was stimulated by induction of acute hypocalcemia using a continuous intravenous EGTA infusion. The EGTA infusion resulted in a significant drop in plasma $\mathrm{Ca}^{2+}$ levels (Fig. 2a) and after $5 \mathrm{~min}$ of infusion the maximum PTH secretory response was obtained (Fig. 2b). After 30 min of EGTA infusion and during maximal PTH secretion, an intravenous bolus of $1 \mu \mathrm{g}$ of $\mathrm{rFGF} 23$ or vehicle was given. The rFGF23 injection significantly increased plasma levels of FGF23 to $1774 \pm 400$ versus $262 \pm 51 \mathrm{pg} / \mathrm{ml}$ in the vehicle group $(p<0.01)$. In spite of these high FGF23 levels, rFGF23 had no suppressive effect on PTH levels during hypocalcemia (Fig. 2b).

\section{Effect of FGFRi on the Plasma Levels of PTH in During Hypocalcemia}

In order to study the effect of FGFRi on PTH secretion in the setting of hypocalcemia, we administered the FGFRi PD173074 or vehicle prior to induction of acute hypocalcemia by EGTA infusion. The FGFRi treatment alone had no effect on plasma levels of $\mathrm{Ca}^{2+}$ (Fig. 3a). The EGTA infusion rapidly decreased the plasma levels of $\mathrm{Ca}^{2+}$ in rats treated with vehicle and in rats treated with FGFRi with no difference between the two groups (Fig. 3a). Again FGFRi resulted in a significant increase in plasma PTH levels from $85 \pm 13$ to $182 \pm 10 \mathrm{pg} / \mathrm{ml}(p<0.01)$. Stable PTH levels were found in the vehicle-treated rats, $104 \pm 22$ versus $124 \pm 25 \mathrm{pg} / \mathrm{ml} \quad$ (Fig. 3b). The parathyroid glands responded immediately to the decrease in plasma $\mathrm{Ca}^{2+}$ with a large and significant increase in plasma PTH levels, obtaining maximum levels already after 5 min of EGTA infusion. In the vehicle-treated rats PTH increased from $124 \pm 25$ to $347 \pm 61 \mathrm{pg} / \mathrm{ml}(p<0.01)$ and in the FGFRitreated rats PTH increased from $184 \pm 10$ to $316 \pm 22 \mathrm{pg} /$ $\mathrm{ml}(p<0.01)$. There was no difference in the maximum PTH secretory response to hypocalcemia in the two groups (Fig. 3b). The plasma $\mathrm{Ca}^{2+}$ concentration continued to decrease at a similar rate during the EGTA infusion in both groups and reached low levels of $0.97 \pm 0.03 \mathrm{mM}$ (vehicle rats) and $0.98 \pm 0.03 \mathrm{mM}$ (FGFRi rats) after $60 \mathrm{~min}$. The maximal plateau of PTH secretion obtained after the transient maximum PTH secretory response was the same in the two groups (Fig. 3b). 

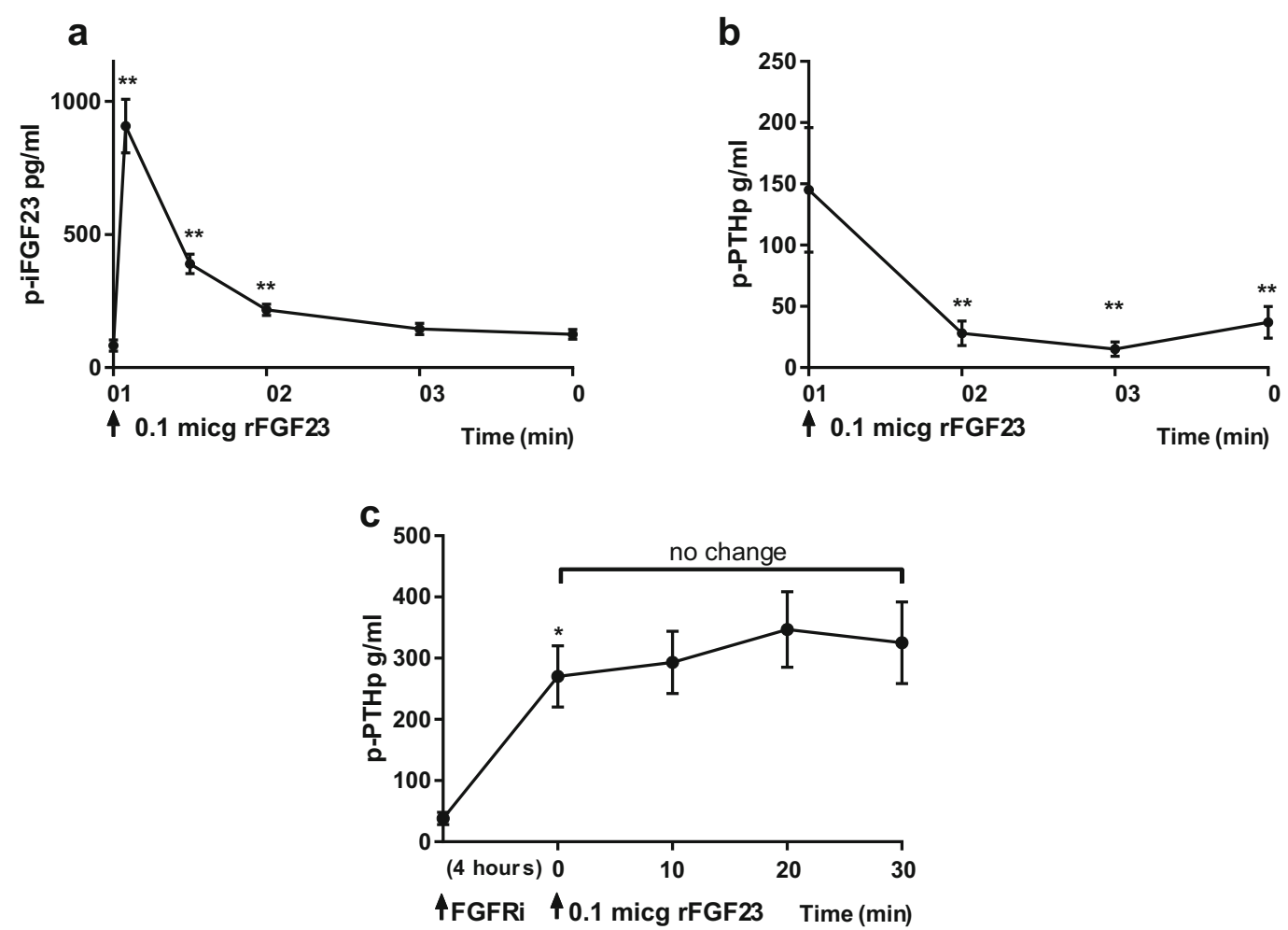

Fig. 1 FGF23 regulates the plasma levels of PTH. a rFGF23 was administered intravenously to normal rats and resulted in a large increase in plasma intact FGF23. b The rFGF23 resulted in a significant decrease in plasma PTH levels after $10 \mathrm{~min}$ and the following PTH levels remained low. c Administration of the FGF receptor inhibitor (FGFRi), PD173074, resulted in a significant increase in PTH levels after $4 \mathrm{~h}$. When rFGF23 was given after prior FGFRi, there was no effect of FGF23 on PTH levels. Data are expressed as mean \pm SEM. ${ }^{*} p<0.05, * * p<0.01, n=4$ in (a and b), $n=5$ in (c)

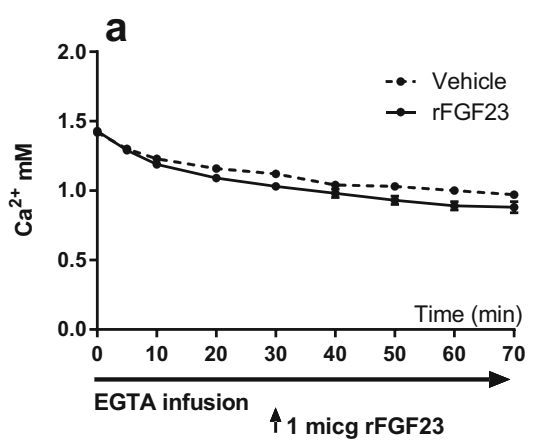

Fig. 2 FGF23's suppressive effect on PTH secretion is abolished at low plasma $\mathrm{Ca}^{2+}$ levels. a Plasma $\mathrm{Ca}^{2+}$ was rapidly decreased by an EGTA infusion $(p<0.001)$. After $30 \mathrm{~min}, \mathrm{rFGF} 23$ was administered intravenously. $\mathbf{b}$ The acute lowering of plasma $\mathrm{Ca}^{2+}$ resulted in a

\section{Discussion}

We used an in vivo model to examine the regulatory function of FGF23 on the plasma levels of PTH and demonstrated that FGF23 has an inhibitory tonus on PTH secretion, but only when the plasma concentration of $\mathrm{Ca}^{2+}$ is within normal range. At low plasma $\mathrm{Ca}^{2+}$ levels, when increased PTH secretion is needed in order to restore

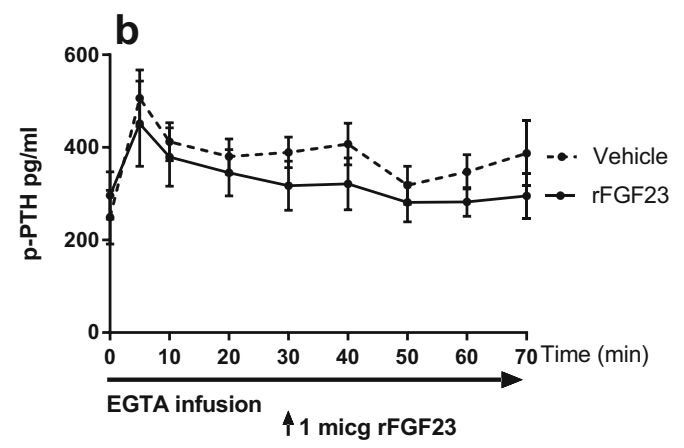

dramatic increase in PTH and a higher plateau of maximal secretion $(p<0.05)$. In hypocalcemia, the rFGF23 had no suppressive effect on the high PTH levels. Data are expressed as mean \pm SEM, $n=6$ in each group

normal $\mathrm{Ca}^{2+}$ levels, this inhibitory effect of FGF23 is abolished. Furthermore, we clearly demonstrated that the suppressive effect of FGF23 in normocalcemia is mediated through the FGF receptor.

A suppressive effect of FGF23 on PTH production and secretion has previously been shown by Ben-Dov et al. They demonstrated a rapid suppressive effect of intravenous FGF23 on plasma PTH levels. This was mediated by phosphorylation of ERK1/2 as an indication of 


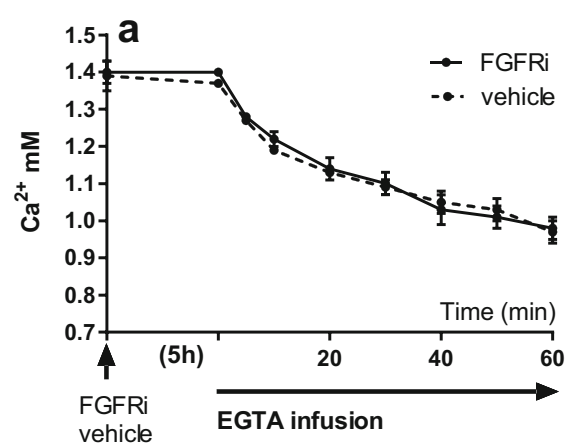

Fig. 3 FGF receptor inhibition has no effect on PTH secretion in hypocalcemia. a FGFRi or vehicle was administered prior to induction of acute hypocalcemia by a continuous EGTA infusion that rapidly decreased plasma $\mathrm{Ca}^{2+}(p<0.001)$. b FGFRi resulted

activation of the MAPK pathway [12]. Furthermore, they injected rats with FGF23 daily for 5 days and confirmed the decrease in plasma PTH levels by a decrease in PTH mRNA. Their studies were done in normocalcemia [12]. A suppressive effect of daily FGF23 injections on PTH levels in normal rats and activation of the MAPK/ERK1/2 signaling pathway has also been shown by Canalejo et al. [21]. Activation of the $\alpha$ Klotho-FGFR complex by FGF23 has been shown to conduct downstream signaling through the MAPK/ERK1/2 pathway and this pathway is activated by FGF23 in the kidney [22]. Krajisnik et al. found ex vivo in bovine parathyroid glands a dose-dependent increase in Egr-1 mRNA, an early response gene of the MAPK/ERK1/ 2 signaling pathway, after co-incubation with two doses of recombinant FGF23 for $1 \mathrm{~h}$ and later a decrease in PTH mRNA and PTH concentration after 12 and $24 \mathrm{~h}$, respectively [14]. Even though they found an early activation of the MAPK/ERK1/2 pathway, the effect of FGF23 on PTH levels was very late as compared to our in vivo results and to the study of Ben-Dov et al. The new findings in the present investigation provide a better understanding on how and when this inhibitory effect of FGF23 on PTH secretion is mediated and stress the impact of normocalcemia in physiological and pathophysiological conditions for the regulation to prevail. We confirm that the effect of FGF23 in normocalcemia is mediated via the FGF receptor in the parathyroid gland as shown in the present investigation by the use of a pharmacological FGF receptor inhibitor.

FGF23 is known to activate FGFR1 isoform IIIc, FGFR3 isoform IIIc, and FGFR4 [11]. Binding of the FGF ligand causes a dimerization of the FGF receptor and induces autophosphorylation of the intracellular domain and activation of downstream signaling of MAPK/ERK1/2, PI3 K/AKT, STAT, and PLC $\gamma$ pathways [23]. We and others have previously shown that the parathyroid gland expresses high levels of FGFR1, FGFR2 and to a less

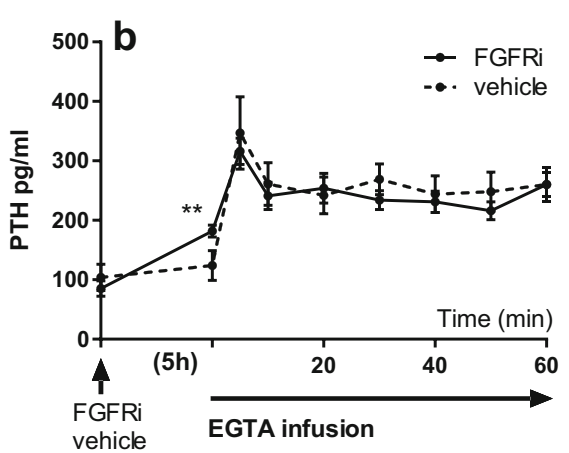

again in a significant increase in PTH levels $(p<0.01)$. The rapid increase in PTH levels in response to acute hypocalcemia was however similar between the two groups. Data are expressed as mean \pm SEM. ${ }^{* *} p<0.01 n=6$ in each group

extent FGFR3 and FGFR4 [13, 15]. We used a pan FGFR inhibitor in the present study and are therefore not able to identify which subtype of the FGF receptors that FGF23 activates in the parathyroid gland. Furthermore, PD173074 also inhibits the tyrosine kinase activity of vascular endothelial growth factor (VEGF) receptor. As such, an effect of this compound on other receptors than FGFR in the parathyroids cannot be excluded.

Upon stimulation of CaSR a number of intracellular signal transduction pathways are activated, among them are phosphoinositide-specific phospholipase C and MAPK/ ERK1/2. Characteristic for PTH secretion is that it is increased at low intracellular $\mathrm{Ca}^{2+}$ levels and suppressed by an increase in intracellular $\mathrm{Ca}^{2+}$ level, where the latter is caused by activation of CaSR [3]. Activation of the FGFRs leads to phosphorylation of PLC $\gamma$, which hydrolyses phosphatidylinositol 4,5 biphosphate to produce inositol triphosphate $\left(\mathrm{IP}_{3}\right) . \mathrm{IP}_{3}$ increases intracellular $\mathrm{Ca}^{2+}$ concentration [23]. FGF23 has been demonstrated to increase the intracellular $\mathrm{Ca}^{2+}$ level in cardiomyocytes [24]. Potentially, this mechanism might explain the rapid inhibitory effect of FGF23 on PTH secretion. Further research is however needed to clarify the signal transduction of FGF23 on intracellular calcium in the parathyroid cell.

Even though most studies confirm the obligatory function of $\alpha$ Klotho in converting the FGFR to be specific for FGF23 signaling, a recent study questions the necessary co-receptor function of $\alpha$ Klotho in the parathyroid gland, as a specific deletion of the $\alpha$ Klotho gene in the parathyroid gland did not abolish the effect of FGF23 [25]. In wildtype mice, FGF23 activated the MAPK/ERK1/2 pathway in the parathyroid glands and suppressed PTH levels. However, in genetically manipulated mice with a specific $\alpha$ Klotho gene deletion in the parathyroid glands, FGF23 activated the calcineurin pathway and suppressed PTH levels [25]. 
Kawakami et al. used genetic-manipulated models, specific deletion of FGFRs and aKlotho in the parathyroid glands of mice, and found in wildtype mice an acute suppressive effect of FGF23 on PTH secretion after $1 \mathrm{~h}$ in accordance to our findings [15]. In the FGFR1-3 and $\alpha$ Klotho knocked-out models, the effect of FGF23 on PTH levels was abolished further supporting our findings of FGF23 signaling through the FGF receptor in the parathyroid gland.

Chronic kidney disease causes disturbances in the mineral balance and concomitant high levels of plasma FGF23 and PTH. In a previous investigation, we administered the FGF receptor inhibitor, PD173074, to uremic normocalcemic rats and found a large increase in plasma PTH indicating that the suppressive tonus of FGF23 on the parathyroid gland is still present in uremia, when plasma $\mathrm{Ca}^{2+}$ is within normal range [26]. Galitzer et al. also found a suppressive effect of FGF23 on the parathyroid glands in uremic rats after 2 weeks of uremia induced by adenine diet [27]. These uremic rats had the same expression of aKlotho in the parathyroid gland as normal rats, but reduced FGFR1 expression. After 6 weeks of uremia, both aKlotho and FGFR1 expressions were reduced and they found no effect of FGF23 on the parathyroid gland [27]. However, other studies suggest that the parathyroid glands in uremia might be resistant to the high plasma levels of FGF23 as shown both in vivo and in vitro by Canalejo et al [21]. It is currently believed that parathyroid resistance to FGF23 could be due to downregulation of $\alpha$ Klotho in the parathyroid gland $[16,27,28]$. However, we did not find a downregulation of parathyroid aKlotho expression in a previous study on uremic 5/6-nephrectomized rats and other researchers have reported a varied $\alpha$ Klotho expression within a uremic parathyroid gland [13, 29].

The present investigation is dealing with the acute minute-to-minute regulation of the $\mathrm{Ca}^{2+} / \mathrm{PTH}$ relationship. Hypocalcemia is a common complication to kidney failure and therefore on the basis of our present results we propose an additional mechanism behind the resistance of the parathyroid gland to FGF23 in uremia, as the low plasma $\mathrm{Ca}^{2+}$ levels overrule the inhibitory effect of FGF23. Further studies are needed to examine the resistance in chronic hypocalcemia, another frequent finding in chronic uremia. Collectively all studies may illustrate the gradual change from normal physiology to a severe pathophysiology with development of a more and more dysplastic autonomous secreting parathyroid gland with downregulation of CaSR, VDR, aKlotho, and FGFR1.

Our results in vivo are in contrast to an ex vivo study on rat parathyroid glands, where FGF23 still had a suppressive effect on PTH secretion and PTH mRNA when the parathyroid cells were incubated at low calcium for $6 \mathrm{~h}$ [21]. These discrepant results may be due to in vivo versus in vitro models. Abolishment of an inhibitory effect during hypocalcemia is known from other endocrine regulatory mechanisms as it has been demonstrated for calcitriol's regulation of PTH transcription [30]. Thus, in chronic hypocalcemia there is a marked increase in calcitriol, which has no suppressive effect on PTH levels; they are significantly increased as well [30]. The mechanism behind these findings has been proposed to be due to the binding of calreticulin to VDR-RXR $\beta$ to VDRE of the PTH promoter [31]. The levels of $\mathrm{Ca}^{2+}$ have been reported also to control FGF23 levels [32, 33]. Therefore, the complex interplay between the calcium and phosphate regulating hormones may also be influenced by the extracellular $\mathrm{Ca}^{2+}$ concentration and thus facilitate the ability of the organism to maintain the crucial $\mathrm{Ca}^{2+}$ homeostasis for normal cellular and organ function [20,34].

All FGF receptors have a cluster of acidic amino acids in their extracellular region. It has been demonstrated that FGFR1 binds $\mathrm{Ca}^{2+}$, although low $\mathrm{Ca}^{2+}$ in the media did not alter the binding of the ligand FGF2 in a cell line [35]. It is however not known if this region affects the interaction in ligand-receptor binding for other FGFRs and ligands. It has been proposed that the binding of a divalent cation will result in a loop configuration in this region that could alter the 3D configuration of the receptor and facilitate ligand binding. Thus a study on cloned FGF receptors found a weaker ligand-receptor binding when rat parathyroid cells were incubated at low calcium concentration [36].

FGF23's suppressive effect on PTH may be part of a classical endocrine feedback loop, where PTH stimulates FGF23 expression via the PTH receptor 1 and possibly by activation of Nurr1 transcription [37-40]. Both hormones have phosphaturic effects, yet they impose a counter regulation on calcitriol with a stimulatory effect of PTH and an inhibitory effect of FGF23. Furthermore, the regulatory loop between FGF23 and PTH seems to be complex and also depending on the extracellular $\mathrm{Ca}^{2+}$ concentration, as shown in the present data. Our study is dealing with the acute effect of FGF23 on PTH secretion, and it has to be emphasized that most clinical scenarios of high FGF23 are chronic and the interpretation from the present acute experiments cannot directly be transferred to image the situation in long-term increase of FGF23 levels.

In conclusion, FGF23 has an inhibitory tonus on PTH secretion when extracellular $\mathrm{Ca}^{2+}$ calcium is within normal range. This regulation is part of a complex endocrine system consisting of FGF23, PTH, and calcitriol, which maintains $\mathrm{Ca}^{2+}$ and phosphate homeostasis. In hypocalcemia, when increased PTH secretion is needed to restore the calcium homeostasis, this inhibitory effect of FGF23 is abolished. 
Acknowledgements The authors would like to thank technician Nina Sejthen. This research was supported by grants from The Danish Council for Independent Research, Herlev Hospital, Rigshospitalet, The Danish Society of Nephrology, The Sophus Jacobsen and his wife Astrid Jacobsen's Foundation, and The Kirsten and Freddy Johansen Foundation

\section{Compliance with Ethical Standards}

Conflict of interest Maria L Mace, Eva Gravesen, Anders Nordholm, Klaus Olgaard, and Ewa Lewin declare they have no competing interests.

Human and Animal Rights and Informed Consent All animal experiments were carried out in accordance with the Guide for Use and Care of Laboratory Animals and were approved by the University of Copenhagen Denmark's Animal Care Committee. This article does not contain any studies with human participants performed by any of the authors.

Open Access This article is distributed under the terms of the Creative Commons Attribution 4.0 International License (http://crea tivecommons.org/licenses/by/4.0/), which permits unrestricted use, distribution, and reproduction in any medium, provided you give appropriate credit to the original author(s) and the source, provide a link to the Creative Commons license, and indicate if changes were made.

\section{References}

1. Lewin E (2004) Parathyroid hormone regulation in normal and uremic rats. Reversibility of secondary hyperparathyroidism after experimental kidney transplantation. Dan Med Bull 51:184-206

2. Brown EM, Gamba G, Riccardi D, Lombardi M, Butters R, Kifor O, Sun A, Hediger MA, Lytton J, Hebert SC (1993) Cloning and characterization of an extracellular $\mathrm{Ca}(2+)$-sensing receptor from bovine parathyroid. Nature 366:575-580

3. Goodman WG (2004) Calcium-sensing receptors. Semin Nephrol 24:17-24

4. Lewin E, Nielsen PK, Olgaard K (1995) The calcium/parathyroid hormone concept of the parathyroid glands. Curr Opin Nephrol Hypertens 4:324-333

5. Huan J, Olgaard K, Nielsen LB, Lewin E (2006) Parathyroid hormone 7-84 induces hypocalcemia and inhibits the parathyroid hormone 1-84 secretory response to hypocalcemia in rats with intact parathyroid glands. J Am Soc Nephrol 17:1923-1930

6. Zhang C, Miller CL, Gorkhali R, Zou J, Huang K, Brown EM, Yang JJ (2016) Molecular basis of the extracellular ligands mediated signaling by the calcium sensing receptor. Front Physiol $7: 441$

7. Geng Y, Mosyak L, Kurinov I, Zuo H, Sturchler E, Cheng TC, Subramanyam P, Brown AP, Brennan SC, Mun HC, Bush M, Chen Y, Nguyen TX, Cao B, Chang DD, Quick M, Conigrave AD, Colecraft HM, McDonald P, Fan QR (2016) Structural mechanism of ligand activation in human calcium-sensing receptor. Elife. doi:10.7554/eLife.3662

8. Kilav R, Silver J, Naveh-Many T (1995) Parathyroid hormone gene expression in hypophosphatemic rats. J Clin Investig 96:327-333

9. Nielsen PK, Feldt-Rasmussen U, Olgaard K (1996) A direct effect in vitro of phosphate on PTH release from bovine parathyroid tissue slices but not from dispersed parathyroid cells. Nephrol Dial Transplant 11:1762-1768
10. Naveh-Many T, Rahamimov R, Livni N, Silver J (1995) Parathyroid cell proliferation in normal and chronic renal failure rats. The effects of calcium, phosphate, and vitamin D. J Clin Investig 96:1786-1793

11. Kurosu H, Ogawa Y, Miyoshi M, Yamamoto M, Nandi A, Rosenblatt KP, Baum MG, Schiavi S, Hu MC, Moe OW, Kuro-o M (2006) Regulation of fibroblast growth factor-23 signaling by klotho. J Biol Chem 281:6120-6123

12. Ben-Dov IZ, Galitzer H, Lavi-Moshayoff V, Goetz R, Kuro-o M, Mohammadi M, Sirkis R, Naveh-Many T, Silver J (2007) The parathyroid is a target organ for FGF23 in rats. J Clin Investig 117:4003-4008

13. Hofman-Bang J, Martuseviciene G, Santini MA, Olgaard K, Lewin E (2010) Increased parathyroid expression of klotho in uremic rats. Kidney Int 78:1119-1127

14. Krajisnik T, Bjorklund $\mathrm{P}$, Marsell R, Ljunggren $\mathrm{O}$, Akerstrom G, Jonsson KB, Westin G, Larsson TE (2007) Fibroblast growth factor- 23 regulates parathyroid hormone and 1alpha-hydroxylase expression in cultured bovine parathyroid cells. J Endocrinol 195:125-131

15. Kawakami K, Takeshita A, Furushima K, Miyajima M, Hatamura I, Kuro O, Furuta Y, Sakaguchi K (2017) Persistent fibroblast growth factor 23 signalling in the parathyroid glands for secondary hyperparathyroidism in mice with chronic kidney disease. Sci Rep. doi:10.1038/srep40534

16. Komaba H, Fukagawa M (2010) FGF23-parathyroid interaction: implications in chronic kidney disease. Kidney Int 77:292-298

17. Mithal A, Kifor O, Kifor I, Vassilev P, Butters R, Krapcho K, Simin R, Fuller F, Hebert SC, Brown EM (1995) The reduced responsiveness of cultured bovine parathyroid cells to extracellular $\mathrm{Ca} 2+$ is associated with marked reduction in the expression of extracellular $\mathrm{Ca}(2+)$-sensing receptor messenger ribonucleic acid and protein. Endocrinology 136:3087-3092

18. Brown AJ, Zhong M, Ritter C, Brown EM, Slatopolsky E (1995) Loss of calcium responsiveness in cultured bovine parathyroid cells is associated with decreased calcium receptor expression. Biochem Biophys Res Commun 212:861-867

19. Nordholm A, Mace ML, Gravesen E, Olgaard K, Lewin E (2015) A potential kidney-bone axis involved in the rapid minute-tominute regulation of plasma $\mathrm{Ca} 2+$. BMC Nephrol 16:29

20. Mace ML, Gravesen E, Hofman-Bang J, Olgaard K, Lewin E (2015) Key role of the kidney in the regulation of fibroblast growth factor 23. Kidney Int 88:1304-1313

21. Canalejo R, Canalejo A, Martinez-Moreno JM, Rodriguez-Ortiz ME, Estepa JC, Mendoza FJ, Munoz-Castaneda JR, Shalhoub V, Almaden Y, Rodriguez M (2010) FGF23 fails to inhibit uremic parathyroid glands. J Am Soc Nephrol 21:1125-1135

22. Martin A, David V, Quarles LD (2012) Regulation and function of the FGF23/klotho endocrine pathways. Physiol Rev 92:131-155

23. Laestander C, Engstrom W (2014) Role of fibroblast growth factors in elicitation of cell responses. Cell Prolif 47:3-11

24. Touchberry CD, Green TM, Tchikrizov V, Mannix JE, Mao TF, Carney BW, Girgis M, Vincent RJ, Wetmore LA, Dawn B, Bonewald LF, Stubbs JR, Wacker MJ (2013) FGF23 is a novel regulator of intracellular calcium and cardiac contractility in addition to cardiac hypertrophy. Am J Physiol Endocrinol Metab 304:E863-E873

25. Olauson H, Lindberg K, Amin R, Sato T, Jia T, Goetz R, Mohammadi M, Andersson G, Lanske B, Larsson TE (2013) Parathyroid-specific deletion of Klotho unravels a novel calcineurin-dependent FGF23 signaling pathway that regulates PTH secretion. PLoS Genet 9:e1003975

26. Mace ML, Gravesen E, Nordholm A, Hofman-Bang J, Secher T, Olgaard K, Lewin E (2017) Kidney fibroblast growth factor 23 
does not contribute to elevation of its circulating levels in uremia. Kidney Int 92:165-178

27. Galitzer H, Ben-Dov IZ, Silver J, Naveh-Many T (2010) Parathyroid cell resistance to fibroblast growth factor 23 in secondary hyperparathyroidism of chronic kidney disease. Kidney Int 77:211-218

28. Kumata C, Mizobuchi M, Ogata H, Koiwa F, Nakazawa A, Kondo F, Kadokura Y, Kinugasa E, Akizawa T (2010) Involvement of alpha-klotho and fibroblast growth factor receptor in the development of secondary hyperparathyroidism. Am J Nephrol 31:230-238

29. Ohkido I, Yokoyama K, Imura A, Utsunomiya Y, Hosoya T, Nabeshima Y (2010) Persistent alpha-Klotho (a-Kl) expression in the parathyroid glands of patients with secondary hyperparathyroidism. Nephrol Dial Transplant 25:1007-1008

30. Naveh-Many T, Silver J (1990) Regulation of parathyroid hormone gene expression by hypocalcemia, hypercalcemia, and vitamin D in the rat. J Clin Investig 86:1313-1319

31. Sela-Brown A, Russell J, Koszewski NJ, Michalak M, NavehMany T, Silver J (1998) Calreticulin inhibits vitamin D's action on the PTH gene in vitro and may prevent vitamin D's effect in vivo in hypocalcemic rats. Mol Endocrinol 12:1193-1200

32. David V, Dai B, Martin A, Huang J, Han X, Quarles LD (2013) Calcium regulates FGF-23 expression in bone. Endocrinology 154:4469-4482

33. Rodriguez-Ortiz ME, Lopez I, Munoz-Castaneda JR, MartinezMoreno JM, Ramirez AP, Pineda C, Canalejo A, Jaeger P, Aguilera-Tejero E, Rodriguez M, Felsenfeld A, Almaden Y (2012) Calcium deficiency reduces circulating levels of FGF23. J Am Soc Nephrol 23:1190-1197
34. Gravesen E, Mace ML, Hofman-Bang J, Olgaard K, Lewin E (2014) Circulating FGF23 levels in response to acute changes in plasma $\mathrm{Ca}(2+)$. Calcif Tissue Int 95:46-53

35. Patstone G, Maher P (1996) Copper and calcium binding motifs in the extracellular domains of fibroblast growth factor receptors. J Biol Chem 271:3343-3346

36. Takagi Y, Shrivastav S, Miki T, Sakaguchi K (1994) Molecular cloning and expression of the acidic fibroblast growth factor receptors in a rat parathyroid cell line (PT-r). Parathyroid cellspecific calcium-dependent change of ligand accessibility and covalent attachment of heparan sulfate glycosaminoglycan to the receptors. J Biol Chem 269:23743-23749

37. Kawata T, Imanishi Y, Kobayashi K, Miki T, Arnold A, Inaba M, Nishizawa Y (2007) Parathyroid hormone regulates fibroblast growth factor-23 in a mouse model of primary hyperparathyroidism. J Am Soc Nephrol 18:2683-2688

38. Lavi-Moshayoff V, Wasserman G, Meir T, Silver J, Naveh-Many T (2010) PTH increases FGF23 gene expression and mediates the high-FGF23 levels of experimental kidney failure: a bone parathyroid feedback loop. Am J Physiol Renal Physiol 299:F882-F889

39. Meir T, Durlacher K, Pan Z, Amir G, Richards WG, Silver J, Naveh-Many T (2014) Parathyroid hormone activates the orphan nuclear receptor Nurr1 to induce FGF23 transcription. Kidney Int 86:1106-1115

40. Fan Y, Bi R, Densmore MJ, Sato T, Kobayashi T, Yuan Q, Zhou X, Erben RG, Lanske B (2016) Parathyroid hormone 1 receptor is essential to induce FGF23 production and maintain systemic mineral ion homeostasis. FASEB J 30:428-440 